\title{
Analyzing Field-Derived Arboreal Spectral Signatures
}

\author{
Samuel G. Jenkins ${ }^{1}$, Peter Oduor ${ }^{2}$, Larry Kotchman³, Michael Kangas ${ }^{4}$ \\ ${ }^{1}$ Moorhead Public Service, Moorhead, MN, USA \\ ${ }^{2}$ Department of Geosciences, North Dakota State University, Fargo, ND, USA \\ ${ }^{3}$ North Dakota Forest Service, Bottineau, ND, USA \\ ${ }^{4}$ North Dakota State University, Fargo, ND, USA \\ Email: sjenkins@mpsutility.com, ’Peter.Oduor@ndsu.edu, Larry.Kotchman@ndsu.edu, \\ Michael.Kangas@ndsu.edu
}

Received 30 January 2016; accepted 17 April 2016; published 20 April 2016

Copyright (C) 2016 by authors and Scientific Research Publishing Inc.

This work is licensed under the Creative Commons Attribution International License (CC BY). http://creativecommons.org/licenses/by/4.0/

(c) (i) Open Access

\begin{abstract}
Orbital platforms spectral sensitivity can be a major limitation in ascertaining detailed identification and mapping of arboreal ecosystems. Field-derived spectral signatures using a narrow-band sensor, for example, ASD (Analytical Spectral Devices, Boulder, CO, USA) FieldSpec ${ }^{\circledR}$ Pro cover a spectral FR (Full Range) of 350 - $2500 \mathrm{~nm}$ exceeding spectral sensitivities of commonly used orbital platforms. The plausibility of deriving a spectral library of trees or forests within a training set is venerable. On the other hand, diagnostic spectral features between tree species or types are inherently difficult to ascertain from orbital platforms. This is so especially when the spectral library is applied to a demarcated region beyond the extents of training set. Basic suborbital limitations in detailed identification of trees and forests are presented in this study. We draw attention to spectral or temporal deficiencies and offer probable solutions depending on preferred or optimal spectral sensitivities. For example, Hyperion with 220 bands $(400-2500 \mathrm{~nm})$, one of the three primary instruments on the E0-1 spacecraft, has narrow bandwidths and covers the entire range of the spectral profiles collected for North Dakota tree species. With a $30 \mathrm{~m}$ spatial resolution, it is still useful in species identification in moderate stands of forest. Hyperion is a tasking satellite with limited passes over North Dakota $(\approx 7 \%$ of total area) limiting its use as a platform of choice for statewide forest resource mapping.
\end{abstract}

\section{Keywords}

Spectral Angle, Spectral Correlation Matrix, Leaf Reflectance

\footnotetext{
${ }^{*}$ Corresponding author.
} 


\section{Introduction}

Greater accuracy and consistency in mapping leaf and canopy reflectance and/or radiance is necessary to fully understand environmental or biophysical characteristics that may govern arboreal vibrancy or senescence. To date the full potential of remotely sensed data analysis for monitoring processes on the earth surface is still not fully employed [1] due to spectral sensitivity limitations on orbital platforms amongst other factors. As a consequence forest dynamics and other arboreal analyses that would immensely benefit from a spectral Full Range (FR) of the electromagnetic radiation are hampered. Moreover, commercially available datasets and those in the public domain have spatial and temporal limitations, as such, an idealized orbital platform may offer a limited analysis of forest cover dynamics.

There has been an increasing need in understanding a) arbor-related Carbon sequestration; and b) regional or global $\mathrm{CO}_{2}$ dominance and its impact on biospherical biota [2]-[9]. At the crux of these studies lie species identification and $\mathrm{C}$ sequestration linkages by analysis of volume growth rates and physiological differences in $\mathrm{C}$ uptake or yield. To address $C$ sequestration per each individual tree species, spectral limitations are not only factors to consider in addition to spatial resolution but also pixel composition. There have been a number of image analysis techniques accommodating mixing problems that have been proposed incorporating Spectral Mixture Analysis (SMA) [1]. SMA seeks to address subpixel fractions by determining component targets that would contribute to an otherwise averaged reflectance or radiance. SMA also requires an increased spectral sensitivity with narrower Full Width at Half Maximum (FWHM), a parameter that aids in spectral matching of a target to a set library spectra. Improving SMA techniques can also in turn vastly improve interpretation and generation of land cover types [10]. In SMA, reflected radiance spectra are mixtures of "pure" (endmembers) spectra, which can be determined using a field spectroradiometer [11]. This cyclic argument therefore further illustrates that for SMA to be effective; it is also prudent to have correct in situ data.

Croft et al., [12], collected leaf reflectance data using an ASD Fieldspec Pro spectroradiometer (400 - 2500 $\mathrm{nm}$ ) for over 300 leaf samples. From their study, they found out that broadleaf canopies had a high performing Maccioni Macc01 Index [13], $\left(R_{780}-R_{710}\right) /\left(R_{780}-R_{680}\right)$ where $R_{n}$ was directional reflectance at wavelength $n$ $\mathrm{nm}$. Spectral data were derived from MERIS (MEdium-spectral Resolution Imaging Spectrometer) orbital platform. Taylor et al., [14] used an ASD Fieldspec Pro System to measure absolute reflectance of target plant material under standardized laboratory conditions and in the field to characterize spectral signatures in the winter, during leaf-off conditions for woodland overstory, and in the summer under full-leaf conditions. They found that leaves from four different habitats produced similar spectral signatures in the visible spectrum (380 - $700 \mathrm{~nm})$, with a characteristic peak of 5.6\% - 7.1\% absolute reflectance at $550 \mathrm{~nm}$ and a steep red edge at $700 \mathrm{~nm}$. Le Maire et al., [15] sought efficient hyperspectral indices for essential forest ecosystem parameters, for example, chrolophyll content of forest sun leaf ( $\mathrm{CHL}, \mu \mathrm{g} \mathrm{cm}_{\text {leaf }}^{-2}$ ), sun leaf mass per area (LMA, $\mathrm{g}_{\text {dry matter }} \mathrm{m}_{\text {leaf }}^{-2}$ ), canopy leaf area index ( $\left.\mathrm{LAI}, \mathrm{m}_{\text {leaf }}^{2} \mathrm{~m}_{\text {soil }}^{-2}\right)$ and leaf canopy biomass $\left(\mathrm{B}_{\text {leaf }}, \mathrm{g}_{\mathrm{dry} \text { matter }} \mathrm{m}_{\text {soil }}^{-2}\right)$. These indices were then applied to two Hyperion images (50 plots) on the Fontainebleau and Fougères forests and portable spectroradiometer measurements with some indices displaying a high relative correlation. Oumar et al., [16] derived field spectra that were resampled to Hyperion sensor to detect Thaumastocoris peregrinus damage. In their study, they explained the significance of normalized indices and spectral indices calculated from the visible and nearinfrared bands in hyperspectral data as key ingredients in assessment of T. peregrinus damage. De Benedetto et al., [17] applied first principal components relating to five bands (green, yellow, red, rededge, near-infrared (NIR) PCs) of hyperspectral reflectance data. They felt that hyperspectral sensors were the most informative of soil and plant properties. The main aim of this study is twofold, a) to establish a spectral identification schema using an ASD FieldSpec ${ }^{\circledR}$ Pro spectroradiometer serving as a rudimentary step in forest or tree species target mapping, and b) to identify orbital platforms that may offer prime data for different forestry applications.

\section{Methods}

\subsection{Spectral Library}

An ASD FieldSpec ${ }^{\circledR}$ Pro spectroradiometer with leaf clip assembly was used to generate the spectral library. In the very near infra-red (VNIR) wavelength range, 350 - $1000 \mathrm{~nm}$, an individual detector for each measured wavelength, is positioned to receive light within a $1.4 \mathrm{~nm}$ bandwidth. The VNIR spectrometer has a spectral resolution of approximately $3 \mathrm{~nm}$ at around $700 \mathrm{~nm}$. In the near infra-red (NIR) wavelength range, $900-2500 \mathrm{~nm}$, 
there are two detectors, which are exposed to different wavelengths of light as a grating oscillates. The first detector measures light between about $900-1850 \mathrm{~nm}$; the second covers the 1700 - $2500 \mathrm{~nm}$ region. The spectral resolution in the NIR range varies between $10 \mathrm{~nm}$ and $12 \mathrm{~nm}$, depending on the scan angle at that wavelength.

The spectral library was constructed during the first three weeks of July, which coincided with mature leafing and a full leaf canopy for typical North Dakota trees and forests. Spectral samples were obtained from Lincoln Oakes Nursery, Bismarck, which is run by North Dakota Association of Soil Conservation Districts and Towner State Nursery, Towner, which is run by North Dakota Forest Service (Figure 1). The schema of our methodology is depicted on Figure 2. Replicate samples were collected in situ (when leaves were attached to the tree) and ex situ where the leaves were deliberately stressed to gauge change in spectral indices. Each sample was
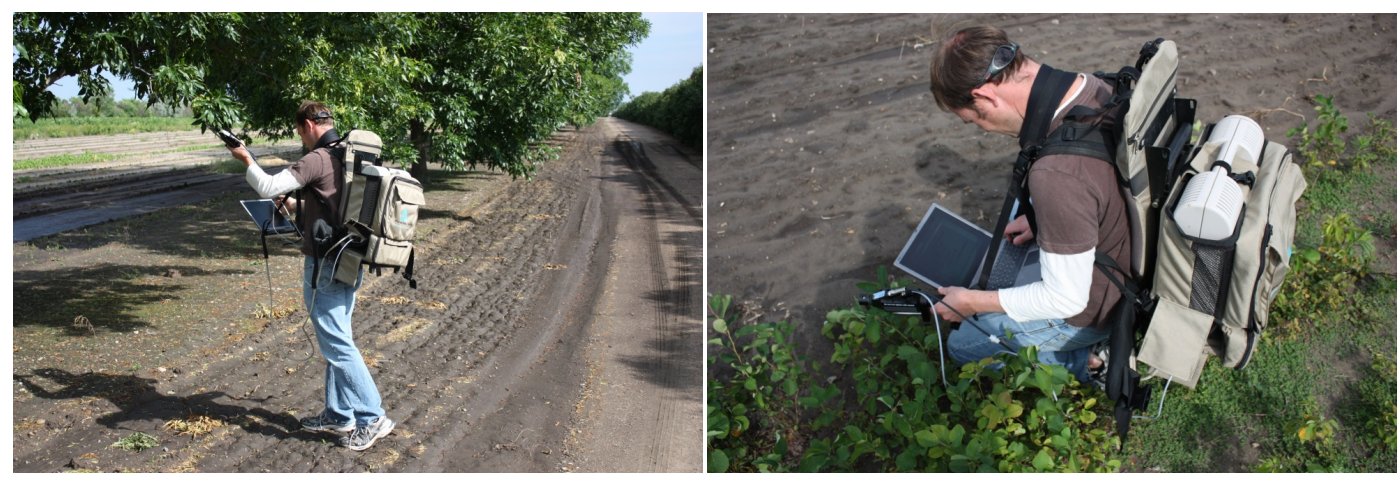

Figure 1. Leaf reflectance measurements using FieldSpec ${ }^{\circledR}$ Pro with leaf clip assembly for mature trees (left) and seedlings (right).

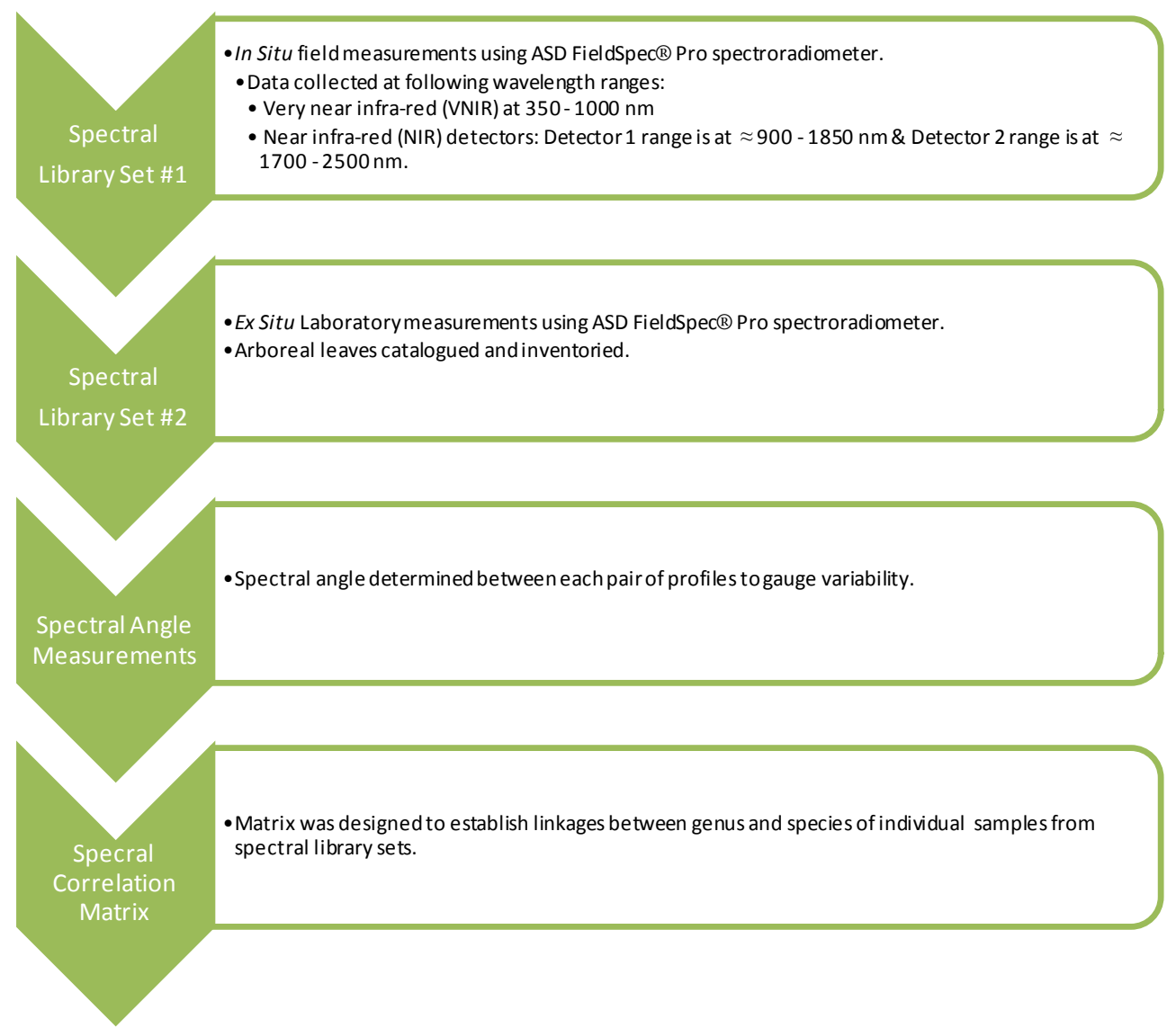

Figure 2. Schematic flow diagram. 
scanned at least four different times on different leaves, with each scan being the average of 25 detector readings. Samples were wrapped in paper towels, bagged in plastic storage bags and stored overnight in a cooler. Stored samples were scanned, the following day, at least eight different times on different leaves. No observable difference was seen between spectral profiles taken from leaves on the plant, immediately taken from the plant or stored overnight. The spectral library generated contained 963 spectral profiles with the distribution shown in Table 1.

Table 1. Genus spectral angle summary table.

\begin{tabular}{|c|c|c|c|c|c|}
\hline \multirow[b]{2}{*}{ Genus } & \multirow[b]{2}{*}{ Profile Count } & \multicolumn{4}{|c|}{ Spectral Angle } \\
\hline & & Minimum & Maximum & Mean & Standard Deviation \\
\hline Lonicera & 1 & 0 & 0 & 0 & 0 \\
\hline Viburnum & 1 & 0 & 0 & 0 & 0 \\
\hline Maackia & 4 & 0 & 0.0143 & 0.00715 & 0.008256 \\
\hline Rhus & 4 & 0 & 0.0426 & 0.0213 & 0.024595 \\
\hline Aesculus & 4 & 0 & 0.0458 & 0.0229 & 0.026442 \\
\hline Cornus & 4 & 0 & 0.0562 & 0.0281 & 0.032447 \\
\hline Celtis & 729 & 0 & 0.1135 & 0.03924 & 0.020444 \\
\hline Juglans & 784 & 0 & 0.0967 & 0.045702 & 0.024575 \\
\hline Malus & 256 & 0 & 0.1103 & 0.052649 & 0.030762 \\
\hline Betula & 1296 & 0 & 0.1431 & 0.061658 & 0.030358 \\
\hline Amelanchier & 9 & 0 & 0.1184 & 0.062177 & 0.050557 \\
\hline Populus* & 5184 & 0 & 0.1864 & 0.067441 & 0.034013 \\
\hline Syringa & 324 & 0 & 0.1505 & 0.068763 & 0.03724 \\
\hline Fraxinus* & 26569 & 0 & 0.2864 & 0.076918 & 0.038314 \\
\hline Robinia & 4 & 0 & 0.1564 & 0.0782 & 0.090297 \\
\hline Tilia* & 4225 & 0 & 0.2022 & 0.081321 & 0.037765 \\
\hline Quercus & 841 & 0 & 0.1856 & 0.084055 & 0.046886 \\
\hline Prunus & 1849 & 0 & 0.2258 & 0.087483 & 0.044309 \\
\hline Juniperus & 1369 & 0 & 0.3544 & 0.093106 & 0.064838 \\
\hline Salix & 625 & 0 & 0.2358 & 0.100163 & 0.068426 \\
\hline Ulmus & 1024 & 0 & 0.3189 & 0.100658 & 0.069814 \\
\hline Shepherdia & 169 & 0 & 0.3039 & 0.10112 & 0.076908 \\
\hline Acer & 15625 & 0 & 0.2833 & 0.112302 & 0.062858 \\
\hline Gleditsia & 256 & 0 & 0.3081 & 0.117027 & 0.085051 \\
\hline Picea & 2809 & 0 & 0.383 & 0.119263 & 0.084207 \\
\hline Caragana & 100 & 0 & 0.2988 & 0.124922 & 0.085244 \\
\hline \multirow[t]{2}{*}{ Elaeagnus } & 576 & 0 & 0.2938 & 0.126828 & 0.099521 \\
\hline & 859476 & 0 & 0.7785 & 0.142895 & 0.094547 \\
\hline Pinus & 4900 & 0 & 0.593 & 0.14878 & 0.119217 \\
\hline Larix & 144 & 0 & 0.4245 & 0.15054 & 0.13318 \\
\hline Hippophae & 121 & 0 & 0.4781 & 0.169353 & 0.130857 \\
\hline
\end{tabular}




\subsection{Analysis of Spectral Library Variation}

To examine the variability of spectral profiles, the spectral angle $(\alpha)$ between each pair of profiles was calculated using the formula shown below [18]:

$$
\alpha=\cos ^{-1}\left[\frac{\sum_{i=1}^{n} t_{i} r_{i}}{\sqrt{\left(\sum_{i=1}^{n} t_{i}^{2}\right)} \sqrt{\left(\sum_{i=1}^{n} r_{i}^{2}\right)}}\right]
$$

where $t$ is test spectrum and $r$ is a reference spectrum. Spectral angle algorithm measures the cumulative differences in reflectance between the test and reference spectrum at each available wavelength. The smaller the spectral angle, the more closely related are the two spectra.

\subsection{Spectral Correlation Matrix}

A simulated correlation matrix was derived to analyze spectral characteristics and to primarily test the degree of relationship between tree species. This was done by computing the spectral angle between samples and generating an invariant spectral angle (spectral angle equal to zero) along the diagonal since the diagonal represents differences between similar pairs. The main desideratum was to establish linkages between genera and species and diminishing outliers or asynchronous data by adoption of a plausible parametric function. The correlation matrix reliability was further enhanced by incorporating 25 iterations of each sample spectral profile over the entire FR and thereafter using multiple repeat readings for the entire 963 sets of spectral profiles.

\section{Results and Discussion}

\subsection{Spectral Library}

Each spectral profile in the library is represented along the $x$-axis and repeated down the y-axis (Figure 3). The result is that the diagonal pairs have the same test and reference spectra, so the calculated spectral angle is always zero (represented by a dark blue color). Spectral angle in this library ranged from 0 to 0.778462 . The largest spectral angles, occurring primarily between coniferous and deciduous leaves are shown in a reddish-brown color. The larger, labeled boxes on the diagonal delineate spectra that belong to leaves from the same genus. The smaller boxes within genus boundaries delineate spectra that belong to the same species.

Figure 4 shows a generalized form of Figure 3 derived by averaging the spectral angle values for each test/ reference pair combination within a genus. With this technique variation within a genus and amongst different

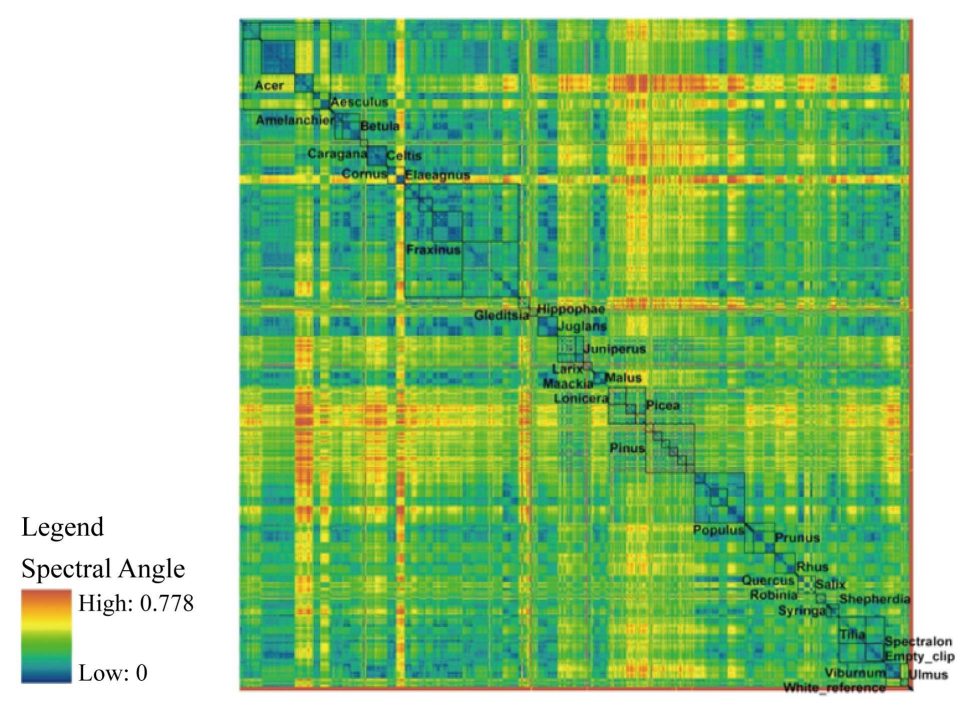

Figure 3. Spectral library spectral angle correlation matrix. 
genera can be more easily assessed. Table 1 describes the variation in spectral angle amongst profiles from the same genus. Genera such as Poplar (Populus), Ash (Fraxinus) and Linden (Tilia) have a low average spectral angle, indicating that one Poplar, Ash or Linden tree looks much like another. Pines (Pinus) have a much higher spectral angle. The conifers, pines, spruce and, to a lesser extent, junipers are easily distinguishable from deciduous trees, and less distinguishable amongst themselves. Table 1 is color coded as colors depicted on Figure 4. Various instrumentation calibrations were performed, for example, instrument optimization to adjust instrument sensitivity was performed automatically for every sample measurement. This is a necessary step to ensure that changing levels of down welling irradiance do not cause the instrument detectors to saturate. Dark current, amount of electrical current generated by electrons within the instrument, was eliminated from base profiles by periodic optimization. The spectral response of the target (leaves) was then automatically computed by dividing its spectral response by that of the reference sample (for example spectralon).

Figure 5 shows variation in spectral angle within test/reference genera pairing that is typically low as shown by the standard deviation value. Notable exceptions are the pines (Pinus) and spruces (Picea) needles which are very difficult to scan with the leaf clip as evidenced by the large standard deviation.

Figure 6(a) was used to elucidate optimum orbital scanners whose imagery would provide the best spectral

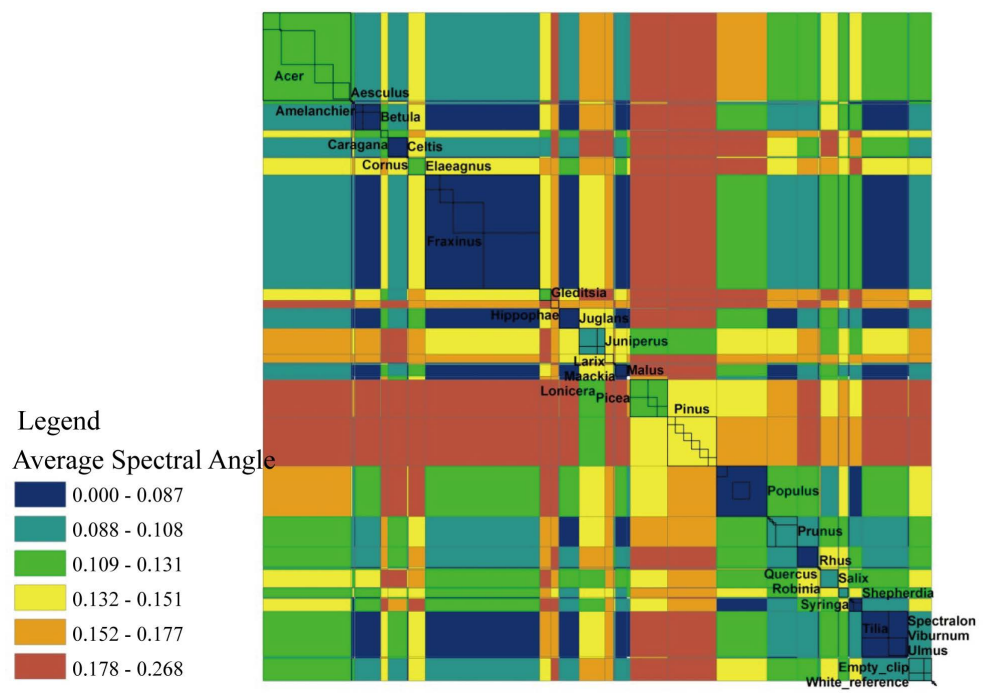

Figure 4. Average spectral angles for genera.

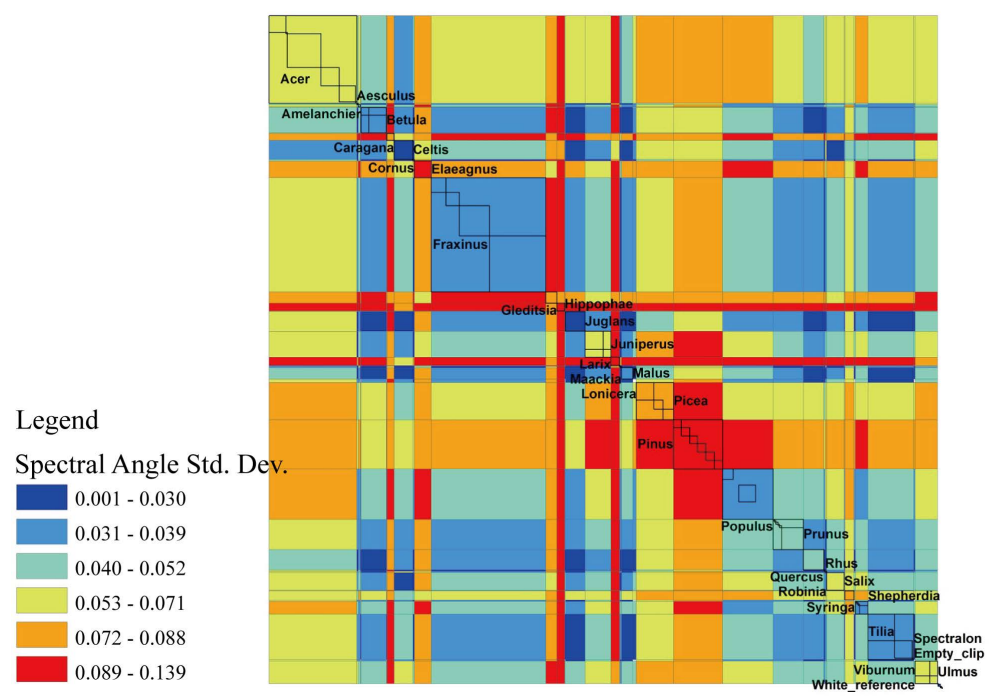

Figure 5. Variation in spectral angles for genera. 


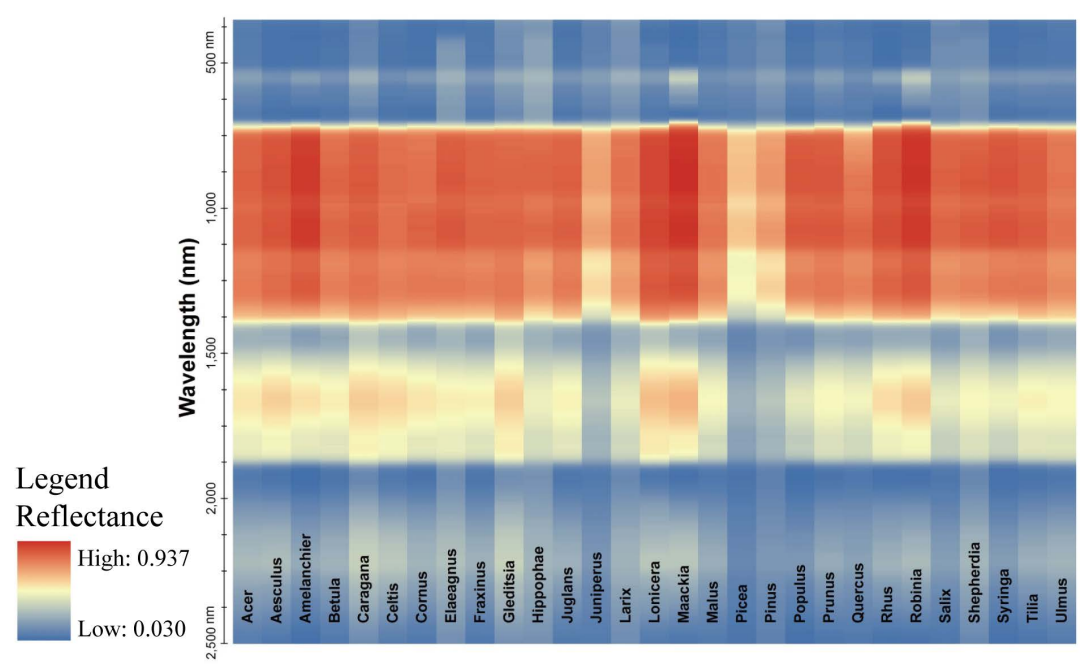

(a)

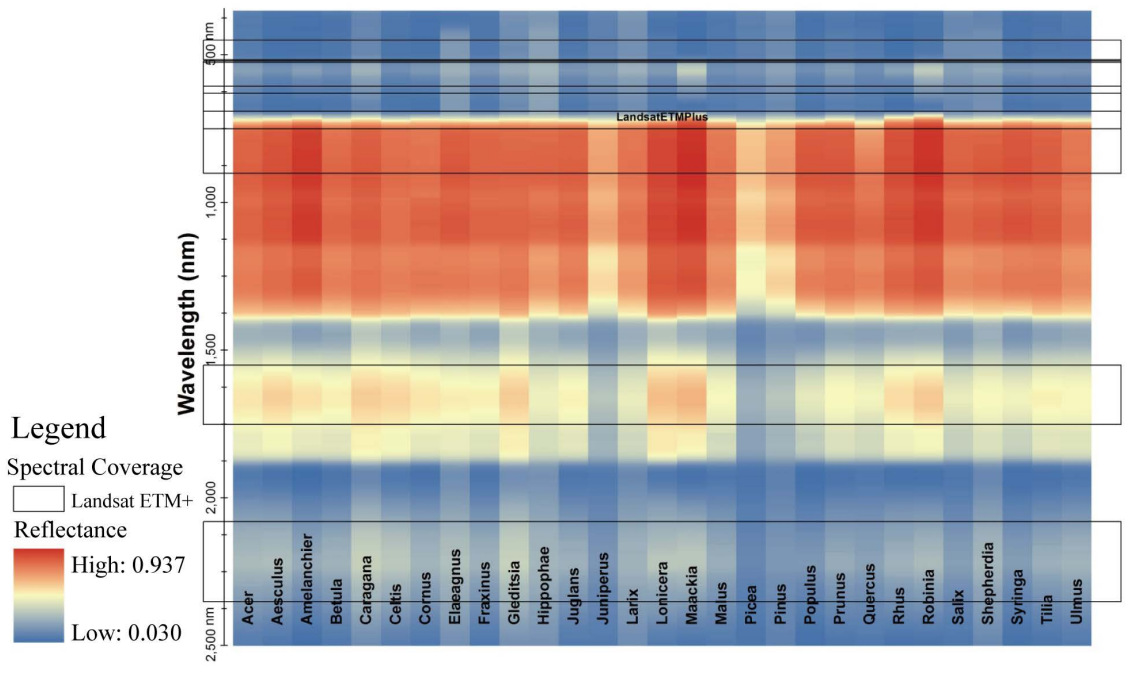

(b)

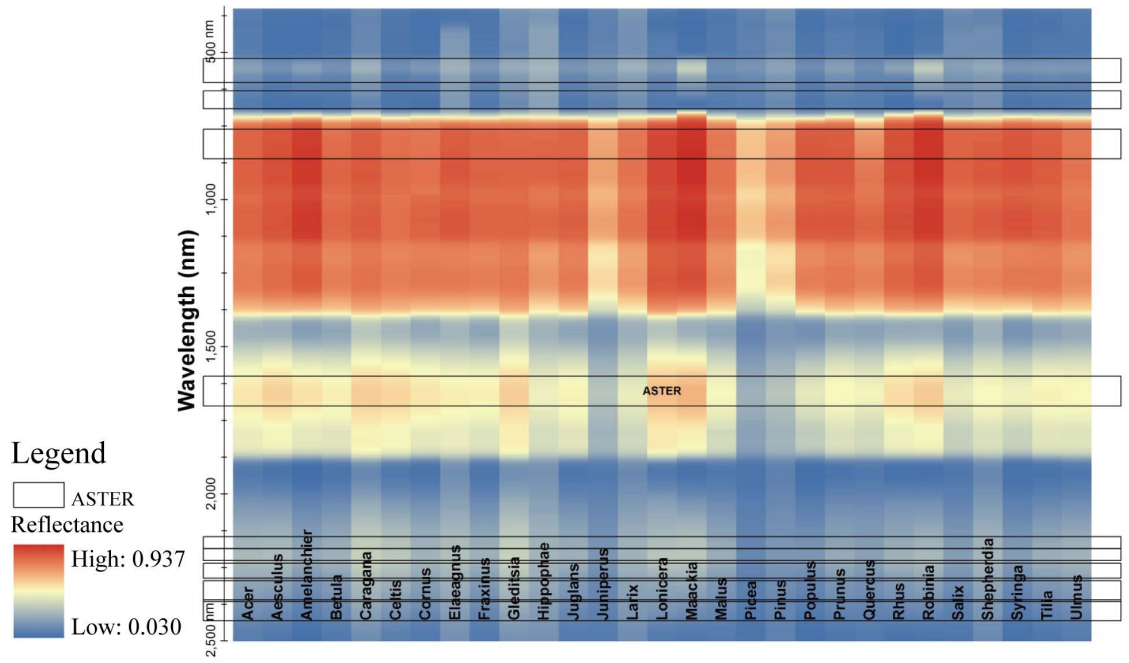

(c) 


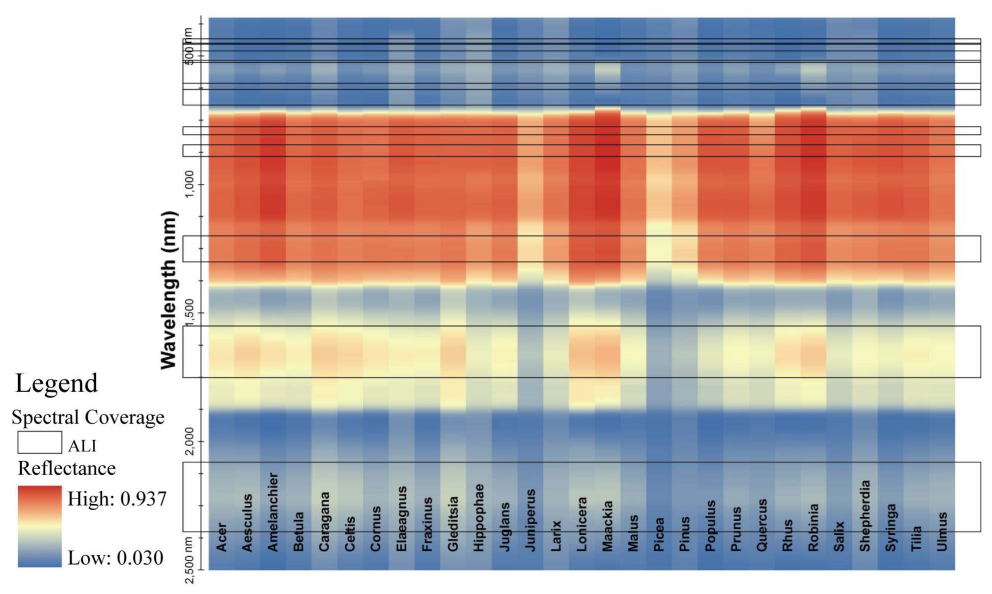

(d)

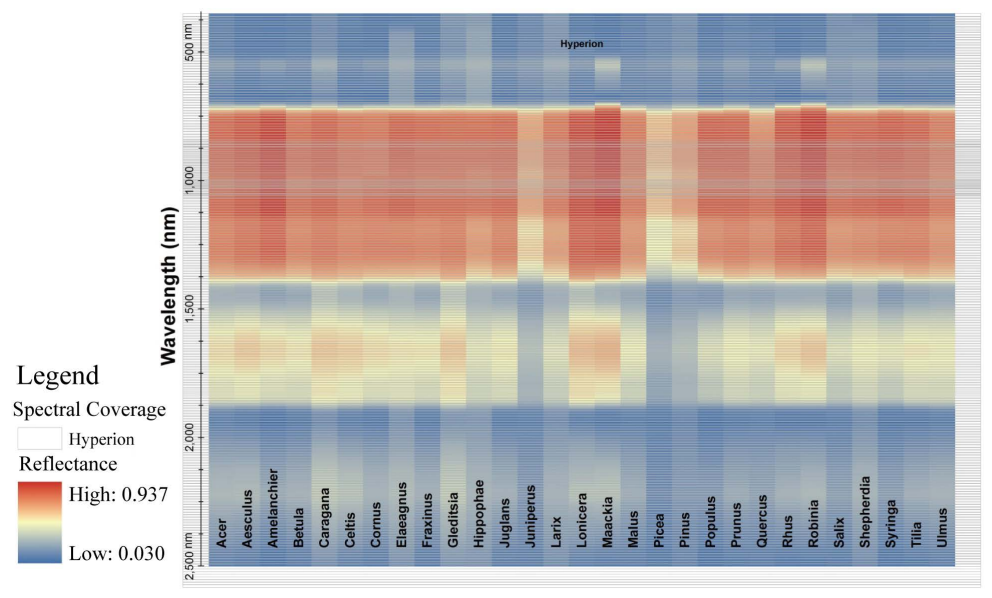

(e)

Figure 6. (a) Genus reflectance variation by wavelength; (b) Spectral coverage of Landsat 7; (c) Spectral coverage of ASTER; (d) Spectral coverage of EO-1 ALI; (e) Spectral coverage of EO-1 Hyperion.

resolution. Figure 6(a) was created by averaging the reflectance value for each profile in a genus at each wavelength. Variation in reflectance at each wavelength can be seen in the variation of hue between the genera. Regions of the spectrum which contain variation among the genera will be useful wavelengths at which to harness reflectance information. The Landsat series of orbital imagers are a commonly used orbital land imaging devices with a significant history. The relatively high revisit frequency (16 days) and its large survey area, with a swath of $185 \mathrm{~km}$, make Landsat images attractive mapping tools [19]. The drawbacks of Landsat images for forest mapping in North Dakota are the relatively coarse spatial resolution, Landsat pixels measure $30 \mathrm{~m} \times 30 \mathrm{~m}$, and the large gaps in spectral information and broad sensitivity of the detectors. The black rectangles on Figure 6(b) represent the spectral ranges of the Landsat ETM+ bands. Variation between reflectance values in each genus within a Landsat band will increase the spectral angle when between two pixels representing trees on the ground. The range of wavelength sensitivity of the Landsat bands, particularly in the infrared range means that, in a spectral profile, variation in reflectance between similar wavelengths will be lost when averaged over all the spectral ranges in the Landsat band. Figure 6(c) shows the spectral range of the Advanced Spaceborne Thermal Emission and Reflection radiometer (ASTER) bands. Variation within each ASTER band will contribute to a low $\alpha$ value (from Equation (1)). The ASTER sensor contains narrow bands in the infrared range, but much wider bands in the visible and near-infrared (NIR) bands. The spatial resolution of the ASTER sensor varies between $15 \mathrm{~m}$ (visible and very NIR) and $90 \mathrm{~m}$ (NIR), so while the NIR bands may be applicable to genera and species identification; they will be of limited use in identifying much of North Dakota's smaller forest acreages. 
Figure 6(d) shows the spectral range of EO-1's Advanced Land Imager (ALI) bands. Unlike the ASTER sensor, the ALI sensor contains narrow band widths in the visible light range, but much wider band widths in the infrared region. A combination of ASTER NIR bands and ALI visible wavelength bands would offer the best spectral combination to maximize Ash tree identification. Figure 6(e) shows the spectral range of EO-1's Hyperion bands. The 220 bands of Hyperion are narrow and cover the entire range of the spectral profiles collected for ND tree species. With a $30 \mathrm{~m}$ spatial resolution it is still useful in species identification in moderate stands of forest. Hyperion is clearly capable of detecting variation contained in the spectral library developed; however since the EO-1 satellite is a tasking satellite with limited passes over certain portions of the Earth and the swath width of the Hyperion sensor is just $7.6 \mathrm{~km}$, Hyperion coverage of North Dakota is only approximately 7\%, severely curtailing its applicability.

\subsection{Applications: Selecting a Training Dataset}

When using remotely sensed data to ascertain land cover or land use categories, it is also essential to provide some estimate of data accuracy. To accomplish this estimation training datasets were derived, for which on-theground data already existed. Images containing both high proportions of Ash tree-crowns and high proportions of other likely tree-crowns were processed as training datasets. On-the-ground data were obtained from various sources including City of Fargo Parks and Recreation department. The Parks and Recreation forest database is maintained as a record of street tree management. Records include the street address and the genus and species of each tree. The database was geocoded using the street address of each tree, yielding a point data layer, Fargo_Street_Trees. Figure 7(a) shows a summary of the Fargo_Street_Trees data layer. Figure 7(b) shows a

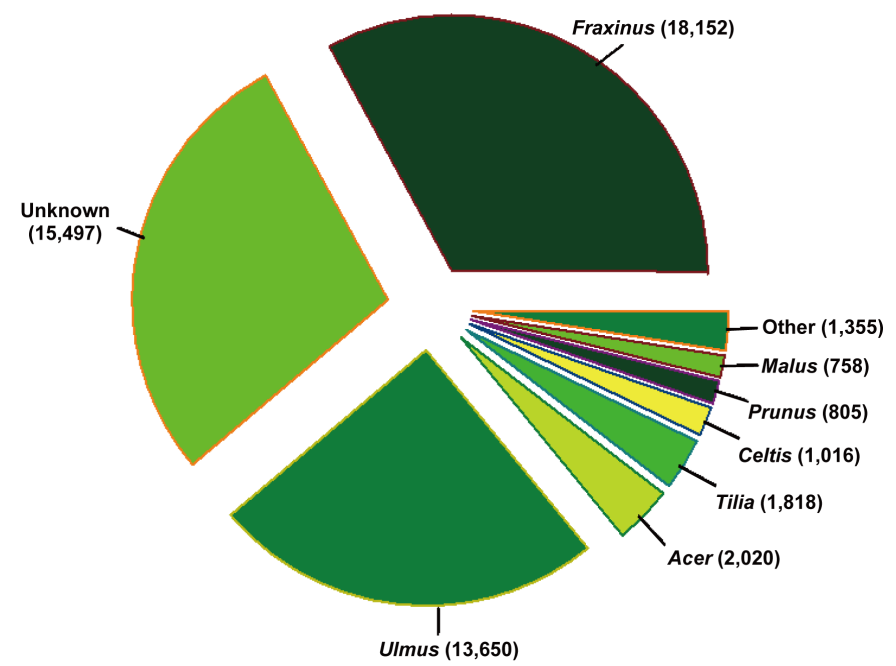

(a)

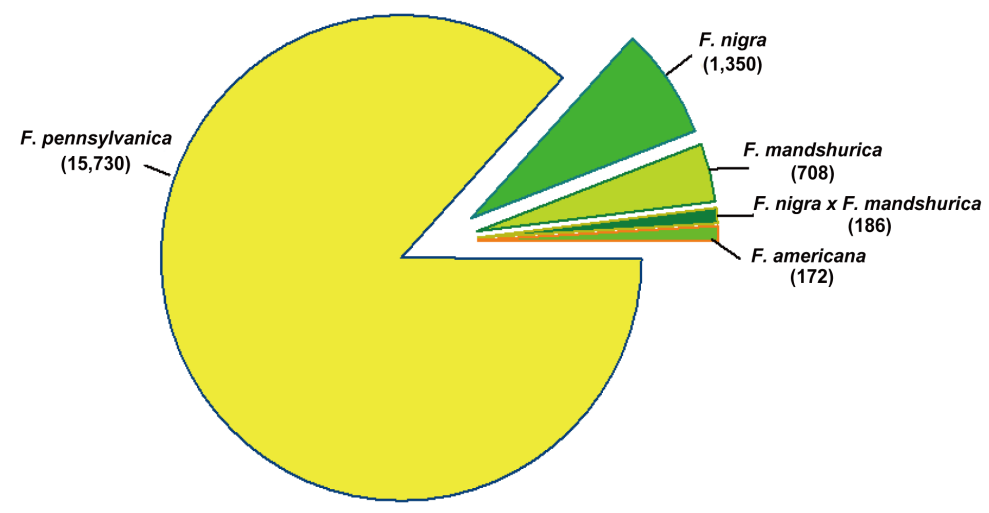

(b)

Figure 7. (a) Fargo street trees by genus. (b) Make-up of Fraxinus street trees by species. 
summary of the Fargo_Street_Trees_Fraxinus data layer. Ash trees are seen throughout the cities of Fargo and West Fargo where they have been planted over the last half century as new and replacement trees (Figure 8(a)). The other notable genus present as Fargo street trees is Ulmus. The bulk of the elms in Fargo are seen in the older suburbs around downtown and towards the north (Figure 8(a)). A third category of trees in the database did not have a recorded genus. These are distributed in a manner more like the distribution of Ash trees than Elms and probably represent ash trees or other genera in the proportions shown in the rest of the database (Figure 8(a)).

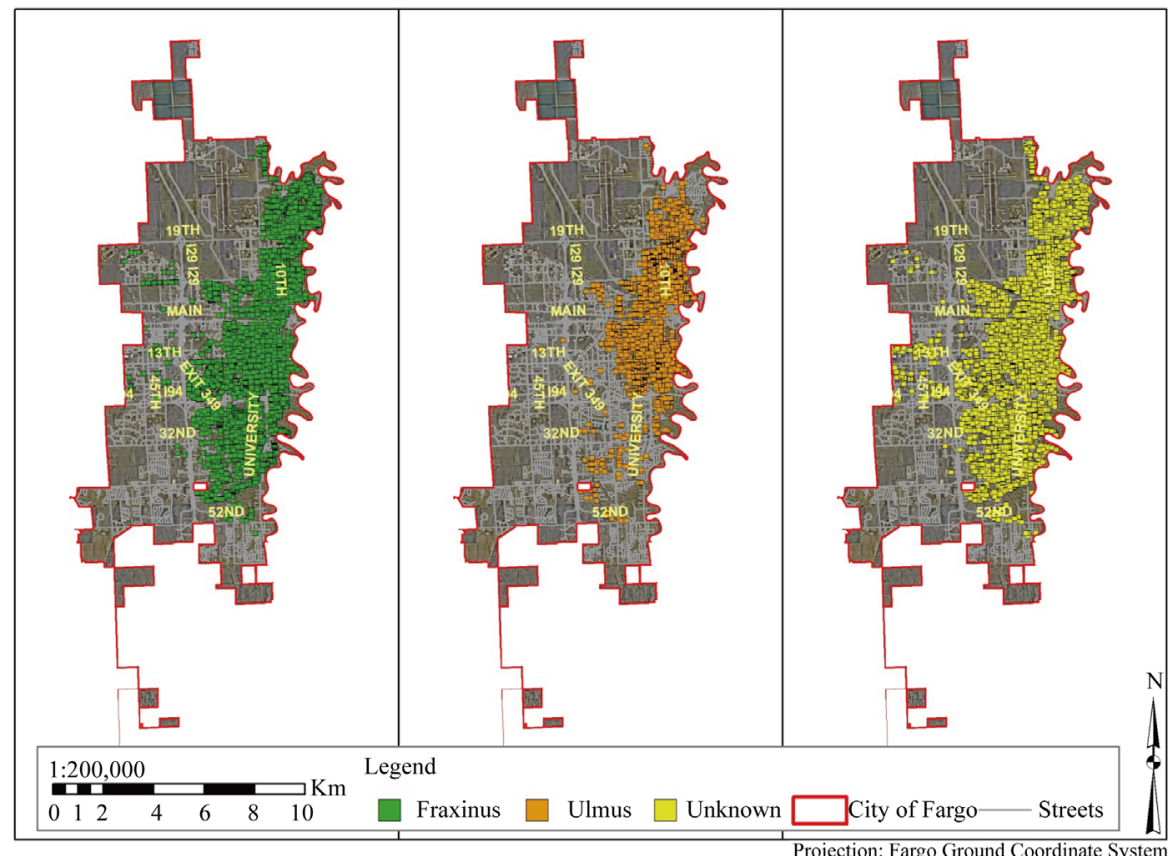

(a)

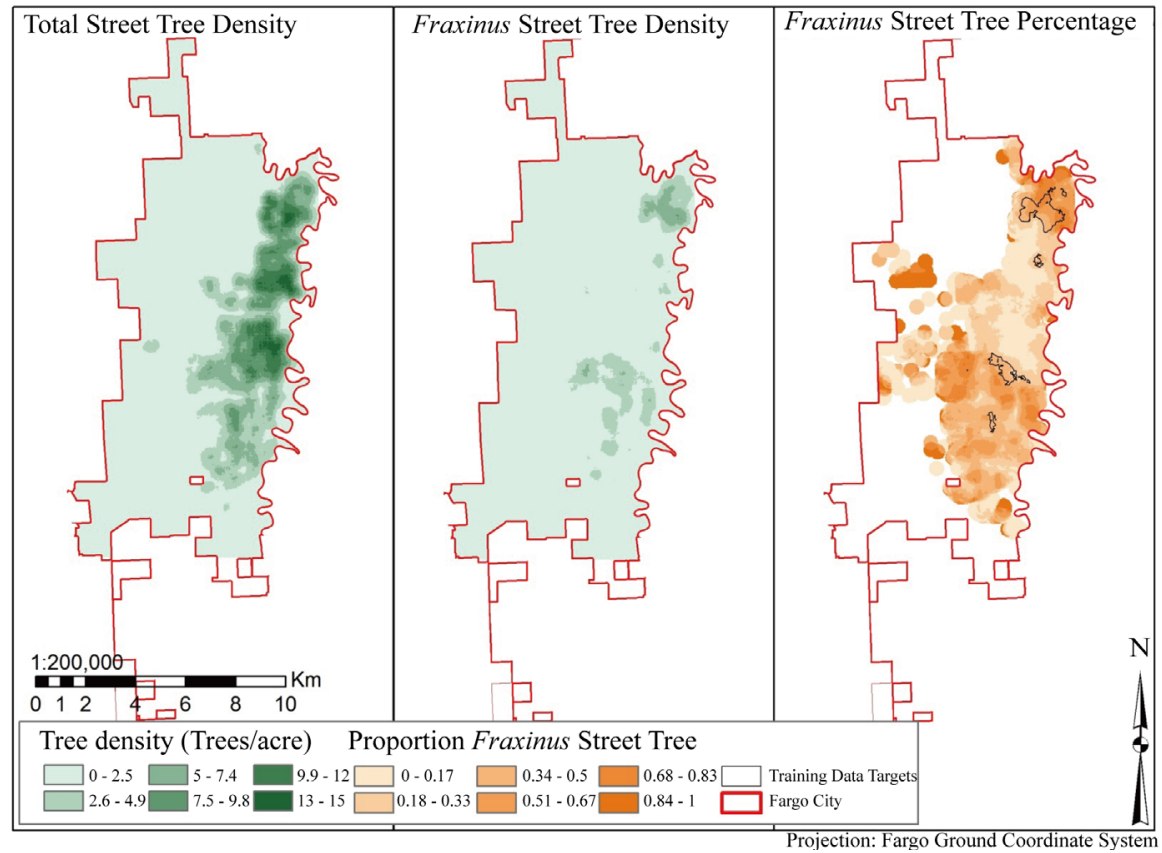

(b)

Figure 8. (a) City of Fargo tree inventory; (b) City of Fargo Fraxinus densities. 
Table 2. Determining training data extents.

\begin{tabular}{|c|c|c|c|c|c|}
\hline File & Northern Extent & Southern Extent & Eastern Extent & Western Extent & $\begin{array}{c}\text { Centroid (Longitude, } \\
\text { Latitude) }\end{array}$ \\
\hline Training_Data_Target_01 & 46.919500 & 46.905612 & -96.770016 & -96.794248 & $-96.782279,46.912921$ \\
\hline Training_Data_Target_02 & 46.863251 & 46.851421 & -96.799174 & -96.813933 & $-96.80588,46.857319$ \\
\hline Training_Data_Target_03 & 46.841892 & 46.835658 & -96.811610 & -96.814912 & $-96.813458,46.83868$ \\
\hline Training_Data_Target_04 & 46.897152 & 46.893342 & -96.782442 & -96.787731 & $-96.785371,46.895122$ \\
\hline
\end{tabular}

A data layer (Fargo_Street_Trees_Fraxinus) containing the location of Fraxinus tree species in Fargo was produced from the Fargo_Street_Trees data layer, by selecting Fraxinus from the genus attribute table and exporting the selected points Density tool with input parameters for: Population field set to None, Output cell size set to 100 feet, Neighborhood geometry set to a circle of radius 1000 feet and areal units of acres selected. The Ash density as a percentage of total tree density was educed by dividing Fargo_Street_Trees_Fraxinus_Density raster layer by the Fargo_Street_Trees_Density raster layer using ArcGIS ${ }^{\circledR}$ Spatial Analyst Raster Calculator tool to yield Pct_Fraxinus_Street_Trees (Figure 8(b)). Selecting areas containing both high proportions of ash tree-crowns and high proportions of other tree-crowns was achieved by selecting areas from the Fargo_Street_ Trees_Fraxinus_Density raster with pixel values greater than 8.17 trees/acre, a value that approximates one tree per average city block, and areas from the Pct_Fraxinus_Street_Trees raster with pixel values between 0.3 and 0.7, using the Spatial Analyst Raster Calculator tool. This aids in discriminating highly forested regions with sufficient Ash trees for training and distinction analyses (Figure 8(b)). The weighted raster was converted to a polygon feature class using Raster to Polygon tool and the polygons with the top-four largest areas were exported as individual shapefiles. Coordinates of each polygon centroid was determined. The extent and centroid of each of the four shapefiles was used as base areal extents to derive training data limits (Table 2). In this inductive manner, extents of a training dataset can then be used to further distinguish tree species.

\section{Conclusion}

From this study, in the event of assessing polydominant forest types and to determine species-dominance due to forcing external parameters; spectral and spatial resolutions must be at absolute optima in order to tease out critical relationships. In such a scenario, an analyst may be able to surmise with a greater likelihood of how, for example, a forest type may transit with respect to climate, insects and/or disease. Furthermore, an increased spectral resolution at an orbital platform may provide a test-bed for modeling studies incorporating temporal information. While orbital and sub-orbital limitations exist, it is still prudent to assess best available platform for elucidating forest species with minimal error.

\section{Acknowledgements}

The research reported in this paper was supported in part by US Department of Agriculture Forest Service award \#10-DG-11010000-011 and CFDA Cooperative Forestry Assistance \#10.664, North Dakota Forest Service, and by the North Dakota State University Department of Geosciences. The opinions expressed in this paper are solely those of the writers and are not necessarily consistent with the policies or opinions of the USDA, the USDA-Forest Service, North Dakota Forest Service, North Dakota State University, and/or CFDA.

\section{References}

[1] Somers, B., Asner, G.P., Tits, L., Coppin, P. (2011) Endmember Variability in Spectral Mixture Analysis: A Review. Remote Sensing of Environment, 115, 1603-1616. http://dx.doi.org/10.1016/j.rse.2011.03.003

[2] Alongi, D.M. (2012) Carbon Sequestration in Mangrove Forests. Carbon Management, 3, 313-322. http://dx.doi.org/10.4155/cmt.12.20

[3] Jones, D.A. and Ohara, K.L. (2012) Carbon Density in Managed Coast Redwood Stands: Implications for Forest Carbon Estimation. Forestry, 85, 99-110. http://dx.doi.org/10.1093/forestry/cpr063

[4] Li, D., Niu, S. and Luo, Y. (2012) Global Patterns of the Dynamics of Soil Carbon and Nitrogen Stocks Following Af- 
forestation: A Meta-Analysis. New Phytologist, 195, 172-181. http://dx.doi.org/10.1111/j.1469-8137.2012.04150.x

[5] Mohareb, E. and Kennedy, C.G. (2012) Direct and Embodied Carbon Sinks for Urban Inventories. Journal of Industrial Ecology, 16, 302-316. http://dx.doi.org/10.1111/j.1530-9290.2011.00445.x

[6] Oduor, P.G., Kotchman, L., Nakamura, A., Jenkins, S. and Ale, G. (2012) Spatially Constrained Forest Cover Dynamics Using Markovian Random Processes. Forest Policy and Economics, 20, 36-48. http://dx.doi.org/10.1016/j.forpol.2012.02.005

[7] Ramirez, K.S., Craine, J.M. and Fierer, N. (2012) Consistent Effects of Nitrogen Amendments on Soil Microbial Communities and Processes across Biomes. Global Change Biology, 18, 1918-1927. http://dx.doi.org/10.1111/j.1365-2486.2012.02639.x

[8] Stavi, I. (2012) The Potential Use of Biochar in Reclaiming Degraded Rangelands. Journal of Environmental Planning and Management, 55, 657-665. http://dx.doi.org/10.1080/09640568.2011.620333

[9] Wiesmeier, M., Sporlein, P., Geusharp, U., Hangen, E., Haug, S., Reischl, A., Schilling, B., Lutzow, M. and KogelKnabner, I. (2012) Soil organic Carbon Stocks in Southeast Germany (Bavaria) as Affected by Land Use, Soil Type and Sampling Depth. Global Change Biology, 18, 2233-2245. http://dx.doi.org/10.1111/j.1365-2486.2012.02699.x

[10] Chen, X. and Vierling, L. (2006) Spectral Mixture Analyses of Hyperspectral Data Acquired Using a Tethered Balloon. Remote Sensing of Environment, 103, 338-350. http://dx.doi.org/10.1016/j.rse.2005.05.023

[11] Peddle, D.R., Hall, F.G. and LeDrew, E.F. (1999) Spectral Mixture Analysis and Geometric-Optical Reflectance Modeling of Boreal Forest Biophysical Structure. Remote Sensing of Environment, 67, 288-297. http://dx.doi.org/10.1016/S0034-4257(98)00090-X

[12] Croft, H., Chen, J.M. and Zhang, Y. (2014) The Applicability of Empirical Vegetation Indices for Determining Leaf Chlorophyll Content over Different Leaf and Canopy Structures. Ecological Complexity, 17, 119-130. http://dx.doi.org/10.1016/j.ecocom.2013.11.005

[13] Maccioni, A., Agati, G. and Mazzinghi, P. (2001) New Vegetation Indices for Remote Measurement of Chlorophylls Based on Leaf Directional Reflectance Spectra. Journal of Photochemistry and Photobiology B: Biology, 61, 52-61. http://dx.doi.org/10.1016/S1011-1344(01)00145-2

[14] Taylor, S.L., Hill, R.A. and Edwards, C. (2013) Characterising Invasive Non-Native Rhododendron Ponticum Spectra Signatures with Spectroradiometry in the Laboratory and Field: Potential for Remote Mapping. ISPRS Journal of Photogrammetry and Remote Sensing, 81, 70-81. http://dx.doi.org/10.1016/j.isprsjprs.2013.04.003

[15] LeMaire, G., François, C., Soudani, K., Berveiller, D., Pontailler, J., Bréda, N., Genet, H., Davi, H. and Dufrêne, E. (2008) Calibration and Validation of Hyperspectral Indices for the Estimation of Broadleaved Forest Leaf Chlorophyll Content, Leaf Mass per Area, Leaf Area Index and Leaf Canopy Biomass. Remote Sensing of Environment, 112, 38463864. http://dx.doi.org/10.1016/j.rse.2008.06.005

[16] Oumar, Z., Mutanga, O. and Ismail, R. (2013) Predicting Thaumastocoris peregrinus Damage Using Narrow Band Normalized Indices and Hyperspectral Indices Using Field Spectra Resampled to the Hyperion Sensor. International Journal of Applied Earth Observation and Geoinformation, 21, 113-121. http://dx.doi.org/10.1016/j.jag.2012.08.006

[17] De Benedetto, D., Castrignanò, A., Rinaldi, M., Ruggieri, S., Santoro, F., Figorito, B., Gualano, S., Diacono, M. and Tamborrino, R. (2013) An Approach for Delineating Homogeneous Zones by Using Multi-Sensor Data. Geoderma, 199, 117-127. http://dx.doi.org/10.1016/j.geoderma.2012.08.028

[18] Research Systems, Inc. (2003) Environment for Visualizing Images (ENVI) User’s Guide. Boulder, 1084 p.

[19] Landsat Handbook. (2011). http://landsathandbook.gsfc.nasa.gov/ 